\title{
A transmissão da Psicanálise na Universidade
}

\author{
Lucas Costa M. Barbosa \\ Pós-graduando em Clínica Psicanalítica pelo IPUB/UFRJ, psicólogo formado pela \\ Universidade Estácio de Sá Niterói e participante do Fórum do Campo Lacaniano em \\ Niterói.
}

Instituição atual: IPUB/UFRJ

E-mail: lucascostambpsi@gmail.com

\begin{abstract}
RESUMO: Do impossível do educar estabelecido por Freud ao algo que se pode ensinar da psicanálise na universidade e que poderia agregar a formação do profissional em saúde mental, o presente artigo de natureza bibliográfica tem como objetivo pensar a transmissão da psicanálise na universidade a partir da literatura psicanalítica fazendo uma amarração com a fala do Professor Dr $^{\circ}$ Pedro Beranger pela UFRJ na Jornada de Psicanálise 2021 do Grupo de Pesquisa em Psicanálise Subjetividade e Cultura (GPPSC). Se a universidade visa a sistematização do saber científico a partir do ensino, pesquisa e extensão como pensar a especificidade da psicanálise que não se pode ensinar, mas antes transmite-se. É crucial, em um primeiro momento, distinguir a Psicanálise da Ciência e pensar a formação do analista para só então discutir como podemos pensar a presença desse saber no contexto universitário.
\end{abstract}

Palavras-chave: Psicanálise; Universidade; Transmissão; Discurso Científico; Formação do Analista.

\section{Introdução}

A partir das provocações do Professor Dr $^{\circ}$ Pedro Beranger na Jornada de Psicanálise de 2021 do Grupo de Pesquisa em Psicanálise Subjetividade e Cultura (GPPSC) coloca-se o caro tema que é a transmissão da psicanálise na universidade.

Se a invenção freudiana situa o Inconsciente para além da cognição e Lacan (1964) partindo dela o nomeia como o evasivo, como o que não se pega, como aquilo que escapole como então pensar a psicanálise? Como ensiná-la já advertidos de o próprio fazer educativo é desde Freud (1937) um impossível.

Freud (1918) também se pôs a indagar sobre o tema que se propõe aqui sendo claro em afirmar que não é a Psicanálise que se ensina na Universidade, apenas algo dela. 
Se ensinar é impossível, cabe, então transmitir como afirma Beranger (2021). Fazer a distinção entre aquilo que é do campo do ensino e o que é da Psicanálise, ou seja, da transmissão é crucial para discussão que se empreender fazer aqui.

No que tange a psicanálise não há ensino e sim, transmissão. Não é que algo da Psicanálise não possa ser ensinado, mas não se trata de saber como o recalque opera ou que traços estruturais diferenciam uma neurose de uma psicose, a questão insta-se na escuta de um Sujeito e toda produção teórica em Psicanálise parte, então, da clínica para a literatura e não o contrário.

Beranger (2021) salienta que Freud era um homem de ciência moderna e simples. Ele também ficou aturdido pelas questões da psiquiatria de sua época quanto a etiologia das doenças mentais. A grande inovação freudiana é transformar saber em questão e, acima de tudo, escutar as ditas loucas de sua época, as histéricas. Freud, médico neurologista, se indaga diante da histérica que põe em xeque o que se sabia sobre a causa das doenças nervosas. Se elas não estavam dissimulando e não apresentavam acometimento orgânico o que dizer sobre a conversão sintomática que manifestavam no corpo que estivesse além do preconceito religioso que as marginalizavam enquanto mulheres possuídas pelo demônio?

Freud, antes de tudo, se pôs a não dizer e a recusar o lugar de mestre sobre os corpos das pacientes, ele se coloca a trabalho, a perguntar, a escutar. De seu não-saber ele formula uma questão que é o que deve mover a verdadeira ciência como aponta Beranger (2021).

Quando se fala de transmissão diz-se de algo que está para além da teoria e tem a ver com o desejo, com a experiência analítica, com algo do Inconsciente que aparece na análise pessoal do analista em formação, bem como no seu estudo teórico e ao atender os casos sob supervisão. Isso circunscreve uma prática e não o corpo meramente teórico.

Ensinar também estaria no campo da cognição, que segundo Beranger (2021), se parte-se da psicanálise onde o Inconsciente é o que domina todo o sistema psíquico, esta é já um artifício de substituição, de deformação. Ao se articular informações, acomodá-las e organizá-las de forma consciente vê-se então a sua deformação.

Esta ideia pode ser conferida a partir de algo muito simples que é dito por Freud (1912) em Recomendações aos médicos que exercem a Psicanálise. Se a associação do paciente é livre, a escuta do analista também não deve fundar-se na cognição ou na lógica, deve evitar-se tomar notas das falas dos pacientes pelo simples fato de que ao fazê-lo faz se uma seleção do conteúdo o que promove aí a obturação da escuta ao inconsciente falseando o que se pode apreender do que ocorre à mente do analisante. 
Antes de abordar a transmissão nas universidades é necessário percorrer alguns pontos como o que vem a ser a psicanálise e até que ponto podemos chamá-la de ciência. É preciso pensar o discurso científico a partir das formas discursivas do mestre e do universitário como Lacan (1969-70) apresenta em seu Seminário 17: O Avesso da Psicanálise e a partir disso também pensar a universidade como efeito desses discursos.

A formação do analista é um dos pontos que precisam ser discutidos nesse percurso. Se a transmissão da psicanálise está em questão na universidade, faz-se necessário interrogar sobre como se forma um analista, não sem deixar de pensar o que é isso. A questão da formação aparece de forma intrincada à transmissão da psicanálise.

\section{A psicanálise: o avesso do discurso científico}

A universidade faz uma sistematização dos conteúdos de uma determinada ciência ou campo de saber e os organiza em um currículo. Em sua relação com os órgãos competentes ela é capaz de fornecer ao aluno que cumpriu esse currículo um título acadêmico, não importa aqui entrar nas especificidades desses, mas destacar que o cumprimento de um currículo dá a determinado alguém um diploma. A exemplo disso, temos a Psicologia estruturada e organizada em seu campo de saber.

Após estudar suas diferentes correntes, a história da ciência, diversas técnicas e teorias a respeito do desenvolvimento, da personalidade e dos inúmeros processos mentais, cumprir a carga horária de estágio entre outros requisitos acadêmicos, sendo aprovado recebe-se ao final do curso o título de bacharel em Psicologia que habilita a procurar a autarquia responsável pelo fazer profissional a exercer a profissão e aí ser chamado, psicólogo.

O Outro intervém aí autorizando o fazer profissional. Em psicanálise, não há um Outro que autoriza o analista que terá que fazê-lo por si mesmo tal como propôs Lacan (1967) na Proposição de 9 de outubro de 1967 a respeito do analista de escola. Deixando a questão da formação para mais adiante, vamos nos ater ao ensino universitário.

Desde Freud (1937) ensinar é um fazer impossível tal como analisar e governar. Há também um impossível nesse ensino nos ditames da Universidade, mas não se descarta que algo da Psicanálise possa ser ensinado e que ela em muito possa contribuir para a formação 
dos médicos, fica a questão de como ela pode ser incluída na estrutura acadêmica (FREUD; 1918).

Freud (1918) é claro em dizer que o psicanalista pode prescindir da formação acadêmica regular e que esse fazer está para além da formação teórica e até mesmo prática que uma universidade poderia oferecer.

A crítica freudiana à formação médica de sua época afirmando que ela em muito privilegia o corpo, mas ignora o psíquico. A psiquiatria, além dessa supervalorização do corpo enquanto biológico deixando de fora o psíquico que permeia o humano, se perfaz de um modo extremamente descritivo, atendo-se apenas a nomear e classificar sintomas sem se interrogar sobre sua causa. Por isso, a psicanálise poderia contribuir para essa formação trazendo uma visão sobre a vida mental ainda que não fosse ela própria em sua transmissão, mas algo dela.

A questão da inserção da psicanálise na universidade perpassa alguns pontos como a questão da formação do analista, que será abordado mais adiante, e do que se entende por ciência. Contrapondo-se ao Discurso do mestre e do universitário, a psicanálise é o avesso e tem como seu objeto de estudo aquilo que a ciência não quer saber.

Lacan (1962/63: p.47) faz uma contraposição entre a epistemologia científica e o que se intenta como objeto em psicanálise. "Não é certo que exista um cosmo, porque nossa ciência avança precisamente na medida em que renunciou a preservar qualquer pressuposto cósmico ou cosmicizante”. Do universal da ciência ao que se propõe ser a psicanálise o que se desponta é o um a um. A distinção feita entre o objeto da epistemologia e o objeto do desejo, inclui-se na discussão a dimensão significante e sua operação sobre o Sujeito.

Do Cosmos à Unheimlichkeit, Lição III do Seminário 10 (LACAN, 1962/63), é a exata contraposição do quer a ciência e a psicanálise. O estranhamento (Unheimichkeit) coloca em cena o embaraço do sujeito na trama cósmica universalizante da ciência. Há algo do gozo singular do Sujeito que faz furo no saber científico, algo que não se pode explicar pelo manual diagnóstico e que escapole a regra. O estranhamento circunscreve um saber do qual não se sabe, um que não pode ser universalizado e não se enquadra nas Condições Normais de Temperatura e Pressão (CNTP).

Diferentemente do discurso científico em geral, a ciência que Freud se propôs a fazer e que Lacan retoma nesse texto, a psicanálise inclui algo da linguagem e ao fazê-lo não recua diante daquilo que a ciência precisa elidir, o sujeito. A ciência faz, então, recortes, ela delimita seu objeto de estudo e se esforça por controlar as variáveis. Enquanto o cientista 
tenta escandir o objeto, defini-lo, quantificar, medir, pesar, o analista inclui que o saber é não-todo, mas a grande diferença é que se renuncia à esperança de tudo saber.

Para falar da ciência, vamos pensá-la a partir de duas modalidades de discurso, a saber, do mestre e do universitário. Antes de falar deles para, enfim, contrapor com o que visa a psicanálise, faz-se necessário uma breve explanação do que vem a ser um discurso em Lacan (1969-70).

O discurso deve ser apreendido como modalidades de fazer laço social e em sua estrutura mínima possui quatro posições nas quais circulam quatro elementos também sendo eles S1, S2, \$ e a. Ao deslocamento dos elementos nas quatro posições da estrutura do discurso em um quarto de giro dão origem as modalidades discursivas que são o do mestre, do universitário, da histérica e do analista, tal como é possível observar no esquema seguinte.

Figura 1: Os discursos

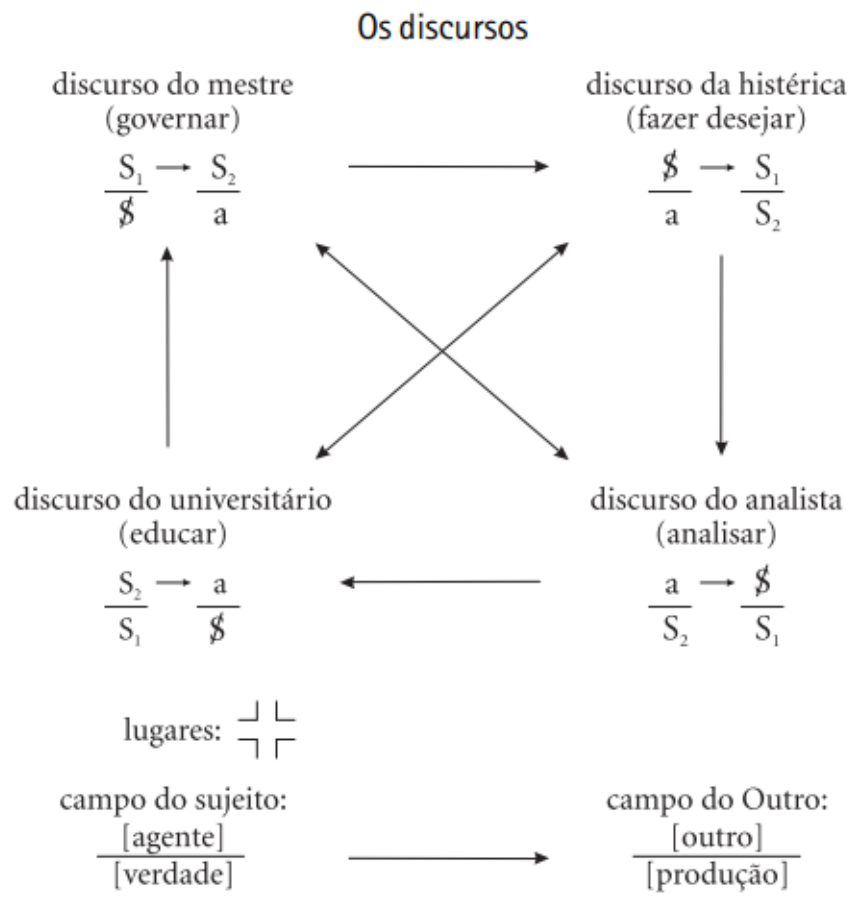

elementos: $\mathrm{S}_{1}, \mathrm{~S}_{2}, \$$, a

Fonte: QUINET; 2009: p.29

Em todo discurso temos um agente que demanda a um Outro que lhe produza algo e está sempre em questão uma verdade que não pode aparecer, há em jogo um certo impossível e os discursos são uma tentativa de fazer algo com este. A presença do objeto a vem para representar algo do gozo que estará sempre presente nas diferentes modalidades de laço social a partir dos discursos. 
Um assinalar que Quinet (2009) faz a respeito da estrutura de um discurso é que do lado esquerdo temos um representante, situado acima da barra, que representa algo situado abaixo da barra para alguém, que está do lado direito na fórmula, a fim de que ele faça uma produção.

O mestre é, para Lacan (1969-70), o discurso primeiro e a partir dele extraímos todos os demais alterando a posição dos elementos em um quarto de giro. A palavra utilizada por Lacan em seu ensino, como indicada na nota do tradutor presente no Seminário 17, é maitre e na língua portuguesa pode ser traduzida como amo, senhor ou mestre. É importante salientar que a mestria da qual falamos diz do governo. Esse discurso diz de uma relação de poder onde um está acima e outro abaixo, uma relação vertical.

Não importa se falamos de um professor que se figura em uma posição de poder em relação aos alunos. Ainda que se trate aí de ensino, o que se está em jogo é o governo, uma relação de poder e, assim, situada no campo do discurso do mestre.

Lacan (1969-70) coloca como agente desse discurso o S1 (significante mestre) e como outro o S2 (saber) e denota-se aí o laço que existe entre senhor e escravo. Mesmo que o mestre tenha o poder, o domínio, é o servo que possui o, savoir-faire, saber-fazer. O servo é roubado de seu saber pelo senhor, sendo essa a operação desse discurso, enquanto o saber do servo é prático, o do mestre é teórico. O que se trata nesse discurso é a questão de onde se situa o saber, há aí uma apropriação por parte do amo com respeito aquilo que diz de uma prática.

Assim, um senhor, que possui o domínio, demanda a um servo, que possui o saber prático, que lhe produza algo que nesse discurso representa-se pelo objeto a enquanto maisde-gozar retomando a conceituação marxista de mais-valia. Não cabe aos objetivos propostos aqui se aprofundar neste conceito ou mesmo do mais-de-gozar, mas nisso que se produz do saber do servo, esse produto também se volta ao amo.

Há ali no laço uma verdade que não pode aparecer, a de que apesar do domínio, o senhor também é um sujeito barrado (\$) e nele também se efetuou a castração. Os próprios limites de seu saber que é puramente teórico representa um furo no discurso. Afinal, o que faria o mestre sem o servo, ou mais ainda, será que ele existiria sem ele? É por isso, que se estabelece aí uma dialética onde as duas figuras (senhor e escravo) interdependem.

O universitário, de acordo com Lacan (1969-70), só se sustenta em ser um mestre a vir-a-ser, por isso que o significante mestre (S1) ocupa a posição da verdade, até que isso ocorra, cabe-lhe estudar o objeto. Nessa modalidade discursiva o agente é ocupado pelo saber (S2) que figura o aplicado estudante universitário que demanda de um objeto (a), outro 
do discurso, que lhe produza um Sujeito (\$), que aqui é resto do objeto. Destaca-se ainda que o universitário ocupa ali o lugar que outrora era do mestre.

Para fins de estudo é preciso fazer caber no objeto, não importa se falamos de um sujeito, ele precisa ser delimitado no objeto de estudos e desta forma o singular do sujeito é o que esse discurso rejeita e consequentemente a ciência (QUINET, 2009). O universitário volta-se ao objeto e quer produzir ali um sujeito, mas esse sujeito não é outro se não um que caiba, que possa encaixotado nos limites de seu estudo, essa operação acaba por mortificálo que em sua dimensão significante abarca algo que foge a lógica universalizante.

Quinet (2009) estabelece uma relação do discurso científico com os discursos que Lacan (1969-70) propõem em o Seminário 17. A ciência quanto ao seu modo de funcionamento assemelha-se ao discurso da histérica no que tange a produção de saber.

Não se trata aqui da neurose, mas do enlaçamento social onde há um agente que demanda a um outro que lhe produza um saber. O cientista nesses termos é aquele que se vê acossado, perturbado, mobilizado pelo real, ele quer saber mais, ele precisa saber e portanto, se debruça a produzir saber tal como o mestre, seduzido pela histérica, faz. Se no discurso do senhor ele governa sobre o escravo, a histérica faz o mestre trabalhar para ela produzindo saber para tamponar seu inconsciente.

Mas em suma, a ciência encarna-se na figura do universitário que é o mestre moderno. Nessa forma discursiva o saber (S2) é o agente e ocupa o lugar que outrora foi do mestre (S1). O que governa a relação é o saber universal da ciência e debaixo de sua égide o cientista é impelido sob um imperativo de tudo saber. Há aqui ainda uma relação de governo tal como entre o senhor e o escravo, pois o cientista trabalha para o saber (QUINET, 2009).

Contudo, a universidade permeia-se não só pelo discurso do universitário na prática do ensino, mas no que tange a docência, aparece aí a figura do mestre, do dono do saber. Está implícita uma relação de poder onde o aluno dependeria de um saber que vem de fora, de Outro que lhe pode aprovar e reprovar.

Lacan (1969-70) faz essa crítica em seu seminário, expondo que há em jogo nesse espaço dito universitário uma relação de poder. Assinala-se que o discurso do analista é antagônico ao do mestre já que este se sustenta de um não-saber o contrário que faz o senhor que expropriou o saber do servo sem reconhece-lhe.

O discurso do analista é o avesso dos demais enunciados até aqui. A começar que é o único que põe a saber inconsciente (S2) no lugar da verdade. E a partir dele que o analista, 
agente, se sustenta e diferentemente de ocultar algo que não pode aparecer, o psicanalista se propõe a sustentar o real tomando como causa o que manca, o que falha (LACAN, 1969).

$\mathrm{O}$ analista se volta ao sujeito, ele o faz advir porque se coloca na relação como objeto, como causa de desejo, como aquilo que determina esse mesmo sujeito. E o local da produção é ocupado pelo significante mestre que é primordial na constituição da cadeia significante inconsciente.

A produção que se extrai no discurso do analista é algo que diz do desejo e da relação do sujeito com o Grande Outro da linguagem (LACAN, 1969).

Enquanto a histérica faz o outro trabalhar produzindo um saber, o mestre rouba o saber do escravo e o universitário encarna o saber tomando o sujeito como objeto de seu estudo, o analista é quem se volta ao sujeito, é por ele que se interessa. Não se trata aqui do universal da ciência, mas do singular do gozo e daquilo que o sintoma diz sobre este.

O saber que sustenta o analista é radicalmente diferente do qual se baseia a ciência e deste modo marca-se uma relação completamente distinta com ele. Se do lado da ciência está o saber totalizante, universal, cosmicizante; do lado do analista, está a Unheimlichkeit, o estranhamento, aquilo que aponta para o real. A psicanálise parte de um saber que é, sobretudo, sobre o singular do gozo. O que faz um analista é implicar um sujeito nesse gozo que se extrai a partir de seu sintoma.

A relação entre saber e gozo é explicitada por Lacan (1969-70) em seu Seminário 17. O saber é sobre o singular do gozo que concerne ao sujeito, sobre algo que o constitui e faz furo frente a possibilidade de tudo simbolizar e trazer significado. Não há nada de mais singular do que o gozo a ponto de Miller (2012) afirma que a máxima lacaniana de que um significante representa um sujeito para outro significante poderia ser reescrita como um significante que apresenta um gozo para outro significante. Miller (idem) no lugar do sujeito coloca o gozo denotando sua íntima relação.

Enquanto os demais discursos não querem saber do furo que faz o gozo demarcando um real presente no laço social, o analista se debruça em seu fazer em interrogar sobre ele convocando um sujeito dividido a falar mais sobre isso.

\section{A formação do analista}

A Psicanálise não deve, então, ser pensada como as demais ciências. Distanciandonos da discussão dela ser ou não científica, é preciso partir da diferenciação que se fez em relação a ciência para a formação do analista. Se não se trata apenas de ensinar ou de uma 
sistematização do saber tal como é feita na universidade e se não se pode autorizar-se o analista a partir de uma instituição formadora, como pensar essa formação?

Antes de partir do básico, é preciso partir da falta! Se há algo que é radical em relação a qualquer outra forma de saber é que a psicanálise inclui o real, e não só isso, mas o sustenta. Se o cientista ao se deparar com o furo, com o sem sentido, mobiliza-se a tampá-lo, a resolvêlo e a responder os milhares de enigmas da vida, o psicanalista só se sustenta partindo de que algo falta e vai continuar faltando.

Agora, do básico, e sendo assim de Freud (1918), a formação ocorre a partir do tripé: análise pessoal, estudo da teoria e os atendimentos supervisionados. E pensar a psicanálise nas universidades como parte do processo de formação coloca como ponto de urgência esse tripé.

O estudo teórico diz sobre o contato com a literatura psicanalítica como Freud (1918) assinala. Esse debruçar não é igual ao estudo de outros saberes pelo simples fato de não estarmos falando de qualquer outro saber e sim da psicanálise como distinguiu-se na sessão anterior. Se antes do básico, o tripé, propomos a falta, é de se esperar que a relação com a teoria não é igual a de outras formações. O que está em questão são espaços onde se pode interrogar e não responder a tudo, algo que circula pelos discursos e não se fixa no discurso nem do universitário ou do mestre.

A supervisão é uma questão pontual de Lacan (1962-63: p. 26) numa passagem do Seminário 10. Não se trata de "oferecer o análogo da interpretação", um complemento para o que se acredita que se sabe sobre o que foi dito pelo paciente, mas de algo que localiza o cerne da psicanálise na prática. Sendo assim, os espaços em supervisão é um espaço de construção a partir da prática.

Nessa mesma passagem, Lacan (1962-63: p.26) localiza seus seminários como estando além da agregação, no que diz respeito a teoria, não se deve pensar nela como um conglomerado de informações, mas como algo que vai ao encontro da prática e que antes de tudo parte dela.

Por fim, voltemos ao início, já que "no início da psicanálise está a transferência" (LACAN; 2003/1967: p. 252) não é possível pensar a formação do analista sem análise pessoal. Lacan (1967) também não o fez e foi claro em destacar que o primeiro lugar que se ocupa aqueles que querem ser analistas é o de psicanalisante. Redundante dizer que Lacan não o fez sem Freud que já em Recomendações aos Médicos que exercem a Psicanálise (1912), salienta-se que é indispensável que o analista passe pelo processo da análise, que ele 
enfrente suas próprias resistências e ignorar isso terá como consequência a obstrução de sua escuta para com as resistências do paciente.

A formação do analista se dá a partir do inconsciente. O caminho da formação passa pela decisão de levar a própria análise as últimas consequências e ao final desse processo o que se encontrará é o analista, isto não é outra coisa senão o que Lacan (1967) formulou como sendo o passe. Se no início há a transferência, ao final há o passe, ocorre no fim de análise uma passagem que faz do psicanalisante um psicanalista.

O passe lacaniano é o dispositivo que se insere na Escola e que permitiria ali então um certo testemunhar do percurso do psicanalisante a se fazer analista. A experiência do percurso é comunicada ali de alguma maneira a escola e é importante salientar que a testemunha não é em um juiz, não é a proposta avaliar se há ali ou não um analista, mas em algum nível há outros que testemunham dessa passagem (LACAN; 1967).

A Escola, em sua proposição lacaniana, não é um Grande Outro que autoriza o analista que deve fazê-lo por si mesmo como enfatiza Lacan (1967) no início de seu escrito a respeito do analista membro. A Escola pode querer garantir a formação de alguma forma dos que a ela se filiam e ao analista cabe decidir por essa garantia ou não. Porém, o que Lacan insta em seu escrito é que juntamente com seus pares o analista se ponha em um fazer ininterrupto que se ocupa em pensar as questões cruciais relativas à psicanálise. Sendo assim, a escola adquire esse papel que amarra os elementos do tripé da formação.

O analista é, como propõe Lacan (1969-70) em seu ensino, uma posição discursiva, modo de situar-se no laço social e deste modo o que diz se há ou não analista não é os diplomas em sua parede, mas algo que só se pode conferir depois, só se sabe do analista depois pelos efeitos que produz em ato sob a fala do analisante.

Porém, antes para se fazer analista é preciso defrontar-se com o que análise radicalmente conduz, seu "des-ser".

\begin{abstract}
Nesse des-ser revela-se o inessencial do sujeito suposto saber, donde o futuro psicanalista entrega-se ao agalma da essência do desejo, disposto a pagar por ele em se reduzindo, ele e seu nome, ao significante qualquer. Porque ele rejeitou o ser que não sabia a causa de sua fantasia no exato momento em que, finalmente, esse saber suposto, ele passa a sê-lo. (LACAN; 1967: p. 259)
\end{abstract}

A partir desse confrontar-se, o psicanalista pode oferecer-se como objeto podendo reduzir-se a significante qualquer a ser tomado pelo analisante para constituir a transferência. Freud (1912) salienta que o paciente toma o analista e o incluí em sua repetição, em sua série psíquica, dando-lhe um lugar em sua fala. Esse significante do Sujeito que se endereça a um 
significante qualquer do analista é o que propicia a transferência e isso diz desse lugar que se oferta a ele.

Sendo assim, a formação do analista fala de outro lugar que não é o de aluno. Não se trata apenas de adquirir um saber teórico como possui o senhor ou ao qual se volta o estudante universitário e sim de uma experiência com o ato analítico. Antes de ser psicanalista se é analisante, antes de analisar há um deixar-se analisar até as últimas consequências.

\section{Do Ensino Universitário à Transmissão da Psicanálise}

Feita a distinção entre o que se propõe o discurso científico e o que é a psicanálise a partir da lógica outra que é a formação do analista, resta ainda pensar a transmissão na universidade.

Nas palavras de Beranger (2021) o espaço universitário é um que se funda em uma proposta democrática de construção, de ampla discussão, de uma abertura às diferenças. Mas, há uma crítica feita por ele a respeito de um certo movimento de retorno a uma lógica verticalizada onde o funcionamento transcorre sob a formulação do discurso do mestre.

Essa verticalidade aparece ainda que se proponhas novas ferramentas de ensino como aponta Beranger (2021) tão simplesmente por serem metodologias de ensino. Se é ensinar, estamos fechados em uma lógica onde o saber é manipulado e o aluno recebe essa informação a partir de um outro, o mestre que o detém. A universidade torna-se "um espaço onde se diz o que o outro deve ser".

Pensando a radicalidade da psicanálise desde Freud não há dúvidas que falar dela é em verdade falar do psicanalista, de um fazer, de uma posição frente ao saber. Desde modo, não é possível deixar de fora a formação do analista que é, em última instância, como aponta Beranger (2021), deformação. "Formar não é informar, não é jogar dentro da forma, já que a Psicanálise nunca foi uma" (BERANGER; 2021: 26'54'’).

Nessa direção, é pensar o processo de análise como receber um sujeito que vem imaginariamente pleno a não ser pela função sinto-mal. O percurso não é outro que não o da queda dessas identificações conduzindo ao final a um des-ser (LACAN, 1967). Se a priori o sujeito sabe disso e daquilo, é assim ou assado, logo vê-se aparecer algo muito corriqueiro na experiência clínica que seria uma enorme sensação de se estar perdido que é contraditória ao ímpeto de se encontrar que os analisantes acreditam tê-los trazido a clínica. 
De igual modo a transmissão da psicanálise propõe entortar, deformar, desarrumar o que é diametralmente oposto ao que quer o mestre que é ordenar ou ao universitário em sua tentativa de delimitar e categorizar o saber organizando-o.

A formação em Psicanálise, como já discutido anteriormente, não se faz sem seu tripé e, por tanto, não sem a prática. Até mesmo diante da leitura da literatura psicanalítica se coloca algo que escapa ao sentido e a lógica. O estudo teórico é intimamente atravessado pelo interrogar e pelo fazer. Quando Lacan (1967) apresenta a proposta da Escola de psicanálise deixa claro que ao membro analista cabe ocupar-se das questões que permeiam a clínica. A processo reflexivo não se faz a partir de um texto, ainda que se conte com ele, mas da prática, da escuta ao analisante.

É quebrando a cabeça ao pensar a clínica que a psicanálise se movimenta. É nisso que está toda sua vivacidade, nessa impossibilidade de tomar nosso objeto de estudo como um artefato de museu. Nesses termos a prática analítica é movimento e jamais conforto.

$\mathrm{O}$ ajustamento da psicologia enquanto uma prática que tenta promover conforto e bem-estar é o que segundo Beranger dá sinais de sua morte enquanto saber. A psicanálise é pulsante em vida, pois salienta que o vivo está a todo tempo em movimento, não há equilíbrio ou homeostase possível quando se trata da pulsão de vida, há força constante que pulsa, que não descansa em direção ao objeto.

A transmissão da Psicanálise contrasta com a noção de ensino ao passo que ele visa não só a acomodação de um saber que vem do mestre, mas também tornar o aluno pleno e não dividido (BERANGER; 2021). O ensino universitário permeado pela lógica capitalista atual transforma o fazer educacional em produto, algo que funcione, tal como Lacan (196970) o propõe ao abordar o discurso do capitalista. Nessa lógica visa-se capacitar o aluno e isso pode ser lido como eco da tentativa de plenificar o sujeito, remover sua divisão.

Mas uma vez a Psicanálise vem no avesso já que interrogar, indagar é reconhecer algo que falta, que rateia no saber. Sendo assim, transmitir só é possível porque algo falta no saber do Outro, porque ele é não-todo. É isso que traz a vivacidade que o discurso do universitário tenta, por assim dizer anular.

Para fins de estudo é preciso fazer caber no objeto, trata-se de delimitar, de controlar variáveis e de não permitir escapulidas. Não importa se trata-se de um ser humano como menciona Quinet (2009), é preciso objetificar para estudar.

A única forma de ensinar a Psicanálise de acordo com Beranger (2021) é psicologizá-la, mas isso não é sem remover dela a radicalidade que a torna algo vivo e 
potente e consequentemente matá-la. Diz-se aqui de retirar dela sua essência viva, sua direção a um corpo vivo.

Psicologizar aqui seria tornar a psicanálise uma prática que se sustente a partir do sentido, da cognição, da consciência. A radicalidade da psicanálise que a torna viva reside exatamente no inconsciente como algo que escapa ao sentido, que se furta de representação total, é sempre parcial, sempre velado em suas formações.

É pertinente resgatar aqui a pergunta feita por Beranger (2021) na Jornada de Psicanálise que se toma como referencial do presente artigo. A que serve a psicanálise no curso de psicologia para que se possa operar a transmissão e não o ensino?

Para Beranger (2021) a psicanálise advém aí como possibilidade de salvar a psicologia da mortificação trazendo a formação a possibilidade de passar da queixa a uma demanda, sair do querer aprender ou se formar para a elaboração de perguntas isso seria implicar a transmissão psicanalítica ao ensino universitário abrindo a possibilidade de inventar e não simplesmente acomodar informações vindas do Outro.

Implicar o aluno na formação fazendo-o passar do querer se formar ao desejo de formação como aponta Beranger (2021) consiste em circunscrevê-lo no movimento de passagem de possuir uma resposta a formulação de questões fazendo circular ali algo do desejo.

\section{Considerações Finais}

Há em questão um impossível no que tange ao ensinar a Psicanálise. Ela em sua radicalidade está para além da acomodação simples de informações que vem do Outro. Diante dessa impossibilidade é preciso, então, passar a invenção que está contida na transmissão.

Em nenhum momento, Freud, ainda que tensionasse um fazer científico, cria um corpo de conhecimentos, não é disso que se trata. E sim, de um fazer, de uma relação com o saber que inclui a falta, que sustenta a divisão e a não plenitude. Longe de capacitar um aluno a exercer a psicanálise, a formação visa reduzir a resto, empoderar a falta e sustentar uma escuta nessa direção.

Dito de outra forma, o analista é aquele que paga o preço de reduzir-se a um significante qualquer a ser tomado pelo analisante. Há nessa modalidade de laço um deixarse pegar pelo outro. Enquanto as demais formas discursivas de articulam para tamponar o 
vazio que constitui o ser falante, a psicanálise, sempre na contramão, vem tomar a falta como causa.

Não se trata, como fora abordado ao longo do texto, de saber sobre tal processo psíquico ou traço estrutural da neurose, mas de escutar um sujeito. No avesso da ciência universalizante, a Psicanálise volta-se a um sujeito que é resto de produção do universitário, tudo aquilo do qual não se quer saber por evadir-se da objetividade e neutralidade proposta por esse molde de ciência o analista se põe a interrogar.

Dessa forma, mesmo que não seja a Psicanálise a ser ensinada na universidade, sua transmissão pode enriquecer muito o processo de-formação nesse espaço corroborando para uma proposta não verticalizada e aberta a construção e não a importação do saber de um que o detém, o mestre.

A psicanálise pode então salvar a psicologia com sua vivacidade trazendo a formação uma certa torção, uma deformação, um acoçamento que faz o sujeito que há na universidade movimentar-se em direção a seu desejo. Desejo este que aparecerá nas questões que formula em seu encontro com um saber que é sempre não-todo.

\section{REFERÊNCIAS BIBLIOGRÁFICAS}

BERANGE, Pedro Mattos. A transmissão da Psicanálise na Universidade. Fórum de Discussões Práxis Psicanalítica. Jornada de Psicanálise 2021. Disponível: (217) A Transmissão da Psicanálise na Universidade | Pedro Beranger. - YouTube. Acesso em: 30 de junho de 2021.

FREUD, Sigmund. (1912a) Recomendações ao médico para o tratamento psicanalítico. In: Fundamentos da Clínica Psicanalítica (Obras Incompletas de Sigmund Freud). Trad. Claudia Dornbusch. $2^{\mathrm{a}}$ Ed. Belo Horizonte: Autêntica, 2020.

. (1912b) Sobre a Dinâmica da Transferência. In: Fundamentos da Clínica Psicanalítica (Obras Incompletas de Sigmund Freud). Trad. Claudia Dornbusch. 2a Ed. Belo Horizonte: Autêntica, 2020.

(1926) A questão da análise leiga. Conversas com uma pessoa imparcial. In: Fundamentos da Clínica Psicanalítica (Obras Incompletas de Sigmund Freud). Trad. Claudia Dornbusch. $2^{\text {a }}$ Ed. Belo Horizonte: Autêntica, 2020.

. (1937) Análise Finita e a Infinita. In: Fundamentos da Clínica Psicanalítica (Obras Incompletas de Sigmund Freud). Trad. Claudia Dornbusch. $2^{\mathrm{a}}$ Ed. Belo Horizonte: Autêntica, 2020.

LACAN, Jacques. (1964) O seminário, livro 11: Os quatro conceitos fundamentais da psicanálise. Rio de Janeiro: Jorge Zahar Ed, 1985.

(1962-63) O seminário, livro 10: A angústia. Rio de Janeiro: Zahar, 2005.

(1967) Proposição de 9 de outubro de 1967 sobre o psicanalista de escola. In:

Outros Escritos. Rio de Janeiro: Jorge Zahar Ed, 2003. 
Zahar Ed, 1992.

. (1969-70) O seminário, livro 17: O avesso da psicanálise. Rio de Janeiro: Jorge

MILLER, Jacques-Alain. Os seis paradigmas do gozo. Opção Lacaniana - Revista Brasileira Internacional de Psicanálise, n. 07, ano 3, março de 2012.

QUINET, Antônio. Psicose e Laço Social: esquizofrenia, paranoia e melancolia. $2^{\mathrm{a}}$ Ed. Rio de Janeiro: Jorge Zahar Ed, 2009. 